\title{
Digital Technologies, Sustainable Open Innovation and Shared Value Creation: Evidences from an Italian Agritech Business
}

DOI: $10.1108 / \mathrm{BFJ}-03-2021-0327$

\begin{abstract}
Purpose: The aim of this research is to explore the mechanisms underlying open innovation success in agri-food businesses and its sustainability. First of all, the authors have explored the importance of 4.0 technologies in data collection from crowds. Second,_how new technologies might drive the development of collaborative strategies with suppliers and the reduction of resource wasting has been observed. The role of 4.0 technologies in increasing the overall supply-chain sustainability is then the main focus of the study.
\end{abstract}

Design/Methodology/Approach: This research builds on a single inductive case study method. The authors performed an in-depth analysis of data from an Italian Agritech distributor. Data - aside from multiple semi-structured interviews - have been collected through several different sources. Results have been summarized in an integrated holistic conceptual framework.

Findings: Findings show how 4.0 technologies allow swift information exchange between consumers, the agritech business, and suppliers. As a result, consumers might demand for new products and, consequently, the agritech business could arrange the new offerings with its suppliers, completing the open innovation and shared value creation circle. Likewise, the possibility to adopt a kind-ofjust-in-time approach may reduce waste of resources. Absorptive capacities and knowledge management capabilities of the agritech business play a fundamental role in open innovation performance, sustainability, and success.

Originality/Value: The research seminally explores how 4.0 technologies and knowledge management techniques could enable open innovation in agri-food businesses. Additionally, how open innovation may foster the development of sustainability-oriented supply-chain strategies has been conceptualized. 
Keyword: 4.0 Technologies; Agritech; Agri-food Businesses Management; Open Innovation; Sustainability; Shared Value Creation.

\section{Introduction}

According to Boston Consulting Group (BCG), the expression "Industry 4.0" refers to a paradigmatic change occurring in any economic sector due to digital technologies availability (Rüßmann et al., 2015). Solutions for smart production and advanced manufacturing (i.e., sensors, actuators, automatic tools such as intelligent robots), Big Data Analytics (BDA), Cloud Computing, Artificial Intelligence, and sophisticated Human-Machine Interfaces (HMI) are more and more available for any kind of business, even without significant infrastructural investments (Rialti et al., 2019a). As a proof, an ever-growing number of businesses from every industry sector are relying on cloud-based solutions provided by specialized firms to increase their competitiveness (by monitoring their supply chain) and to improve the efficiency of their internal operations (Xu et al., 2018). The use of cloud-based solutions offers the opportunity to develop integrated production systems without the hassle of developing parallel architectures or the need to re-train the whole workforce (Cotet et al., 2020). Cloud-based solutions, as well as the use of virtual machines, allow to perform data collection and BDA by simply using an internet connection and a traditional PC. Similarly, most virtual platforms are based on Oracle, SAP, or SparQL interfaces that are widely used in most businesses, thus making the systems extremely scalable (Rialti et al., 2018).

In such a technology-pervaded context, even the agri-food industry started to adopt innovative technological solutions. While such an occurrence may seem counterintuitive - i.e. , businesses in the agri-food industry are traditionally averse to radical innovations (Cillo et al., 2019) - technologies may dramatically influence how such businesses are run. First, through BDA many agri-food firms improved soil productivity, identifying which parasites are more 
prone to attack their harvests (Wolfert et al., 2017). Second, the sensors and actuators have made farmers more capable of managing scant water resources by monitoring the exact amount of water every plant is receiving (Sousa-Zomer and Miguel, 2018). Moreover, blockchain protocols enabled agri-food growers to trace all the passages of bringing agri-food to tables, consistently improving agri-food quality, and reducing waste (Tiscini et al., 2020). Finally, automation started to diffuse in harvesting procedures and production or packaging processes (Maksimović et al., 2015). In this sense, the number of agri-food businesses adopting one or more of 4.0 technologies increased by more than $250 \%$ in a short span of about three years in the EU-27 (Agrifood.tech, 2018). Similarly, over the last decade the UK Government invested more than $£ 160$ million in initiatives to support agri-food businesses' digitalization process (UK Government, 2013).

Among the main consequences of such a technological evolution, scholars observed how with these new digital technologies agri-food businesses increased the amount of collaborations with their partners (Rialti et al., 2019; Kafetzopoulos et al., 2020). Digital technologies, indeed, allow businesses to collect more information from internal processes as well as external sources. Accordingly, this new internal/external information enabled agri-food businesses to know better about the preferences of their customers and, therefore, simultaneously plan joint strategies with their suppliers (Annosi et al., 2020a). For example, nowadays an agri-food business may identify consumers' preferences via predictions based on historical databases and coordinate in real-time with a supplier to adjust the production processes.

The pertinent literature showed how the digital era fosters the adoption of open innovation (OI) strategies in the agri-food industry (Bresciani, 2017; Santoro et al., 2019). In this way, digital technologies become a key factor in the "opening" of agri-food business through the improvement of relationships with business partners (Cillo et al., 2019). Because 
of these technologies, new collaborations are flourishing among businesses. Similarly, new customers in the new and emerging markets can be contacted and involved. This interplay between external and internal knowledge - which stands at the base of OI - is then fully enabled by technologies capable of ensuring fast bi-directional communication and data collection (Bogers and Jensen, 2017; Grimsby and Kure, 2019). The amount of research on technologydriven OI in the agri-food industry is thus increasing at a significant pace (Miglietta et al., 2017; Bogers et al., 2020). The main results of these studies show how technology-driven OI may improve agri-food businesses performance and foster the development of new products (Lefebvre et al., 2015; Grimsby and Kure, 2019).

This notwithstanding, to a large extent the extant research is either theoretical or is based on the cases of specific products developed through OI (Bresciani, 2017; Bogers and Jensen, 2017; Bogers et al., 2020). Further, scholars have mostly focused on challenges faced by agrifood businesses either to adopt digital technologies or to start OI initiatives (e.g., how to use crowdsourcing platforms; see Cillo et al., 2019). Several gaps exist in this specific stream of literature. First of all, it is necessary to better explore the phenomenon at an organizational micro-level. The mechanisms allowing the success of OI strategies, as well as the role of technologies in improving information flows, need to be explored building on best practices. Next, it is fundamental to understand how crowdsourcing might foster the development of OI strategies in the agri-food business through existing knowledge-sharing mechanisms. In particular, the ways through which Sustainable OI (S-OI) may foster the creation of shared value between stakeholders participating in the supply chain need to be investigated at a deeper level (Kamble et al., 2020). Building on these gaps, this research aims to provide an empirical assessment of the role of crowdsourcing-based OI in shared value creation in the agri-food industry. Hence, the overarching research questions are: 
RQ1: How can crowdsourcing-based S-OI foster shared value creation in the agri-food industry?

RQ2: What is the role of digital technologies in such an innovative process?

To answer these research questions, the present research will build on the case study of an Italian Agritech business, which is an agri-food business integrating digital technologies in the management of their internal processes and supply-chain (Lowry et al., 2019). In order to extrapolate relevant insights, an in-depth case study procedure has been adopted. The authors have followed a qualitative and inductive approach in the extraction of results; thus, the conclusion of the research will deal with the development of an interpretative framework unwinding the phenomenon (Cavaye, 1996).

This paper is structured as follows. The next section is a literature review on technologydriven OI and S-OI in the agri-food business. Then, the authors provide an overview of the agritech business and its potentially disruptive impact on the agri-food industry. The fourth section the contains the information about the selected case and the methodological analysis. The fifth section deals with the discussion and implications of the findings. Finally, the last section presents limitations of the present research and suggestions for future research.

\section{Crowdsourcing-Based Open Innovation and Sustainable Development: The Next Great}

\section{Challenge in Agri-food Industry}

According to Hervas-Oliver et al. (2021), innovation has been traditionally explored by using internal perspectives such as organizational learning and knowledge-based view (KBV). However, the debate has experienced a significant paradigm shift by moving the focus to external resources of innovation (Chesbrough et al., 2021). This changing perspective is robustly coupled with the notion of OI, whereby companies increasingly use external resources 
to accelerate their innovation processes (Fertő et al., 2016). Indeed, OI has been defined as the ability of companies to capture and integrate external ideas with internal knowledge to develop new products or processes (Chesbrough, 2003). Following this perspective, companies should both develop internal processes to incorporate external know-how into their operations and create appropriate channels to exchange knowledge with surrounding organizations (Chesbrough et al., 2021). Cooperating in innovation allows firms to expand in markets by offering new products, reducing costs, and expanding experience and creativity (Costa et al., 2016). Different stakeholders can be included in OI processes such as competitors, customers, universities, and research centers (Tardivo et al., 2017). Thus, OI can occur both in businessto-business (B2B) and business-to-consumer (B2C) contexts. B2B knowledge flows originate from cross-enterprise collaboration. Differently, in B2C contexts, firms research innovative information and ideas directly from the public (Chesbrough, 2020). Recent studies emphasize the potential of the public to generate, evaluate, and select the most promising ideas (Cheng et al., 2020). Wisely, to reduce potential inefficiencies in innovation processes, several companies outsource idea generation and evaluation to online crowds (Cheng et al., 2020). Companies can approach the crowd using crowdsourcing platforms (i.e., Crowdsourcing by Google, Ideanote, QMarkets, Amazon Mechanical Turk). Through the adoption of these platforms, the crowd can actively participate in the innovation process of a sponsoring organization by co-creating new products. Co-creating ideas and products has multiple benefits such as waste reduction, higher consumer engagement, and more sustainability (Piller, 2006). According to Agrawal and Rahman (2015), in value co-creation consumers can assume several roles, including: (a) coideators: customers present innovative ideas; (b) co-evaluators: customers evaluate ideas through comments and feedback; c) co-testers: customers test new products, and the company receives immediate feedback. Hence, the implementation of crowdsourcing practices implies entrusting consumers with these roles to generate new ideas and co-create value jointly. 
Even though the concept of OI has been mainly analyzed in large and high-tech companies, a growing body of literature on Small and Medium Enterprises (SMEs) emerged, demonstrating that OI also exists in smaller organizations, such as the agri-food businesses (Galati et al., 2016; Santoro et al., 2017; Franceschelli et al., 2018). Indeed, agri-food businesses are facing impressive challenges stemming from several social and environmental changes (Galati et al., 2016). To begin with, consumer lifestyles have radically changed, requiring companies to come up with new offerings (Cillo et al., 2019). Consumers are increasingly opting for specialized diets that respond to their desires to eat healthy agri-foods. According to Cillo et al. (2019), most consumers are proponents of positive nutrition that will improve their health. In this changing context, agri-food companies have to engage consumers and other supply chain players in developing appropriate products (Costa et al., 2016). Furthermore - due to the COVID-19 pandemic - food quality and safety have become important decision criteria for most consumers (Wicaksono et al., 2021). Agri-food businesses could engage in innovative partnerships to improve product quality and safety (Saguy, 2016). Finally, further dimensions concern sustainability and environmental issues. Society has become aware of the importance of acting on several fronts related to sustainability, and any industry must address social development and sustainability, including agribusiness (Bogers et al., 2020). Indeed, natural resources are limited, while human needs are constantly increasing. Socioeconomic transformations and increasing competition pose challenges to agri-food companies, requiring innovative and creative business models (Bresciani et al., 2016; Santoro et al., 2017).

Hence, these changes in social behavior and attitudes have exposed agribusinesses to severe competitive challenges, forcing them to engage in innovative and "open" actions (Bresciani, 2017; Santoro et al., 2017). Specifically, through OI agribusinesses can engage consumers in developing appropriate and personalized products, enhancing their preferences and meeting their dietary needs (Costa et al., 2016; Soto-Acosta and Cegarra-Navarro, 2016; 
Franceschelli et al., 2018). Moreover, there are examples of OI where companies have codeveloped biosensors to monitor processes, quality, and product safety (Saguy, 2016).

In addition, OI has been proven to be a viable response to agribusinesses quest for increased sustainability. Indeed, the combination of sustainability and OI has resulted in the concept of sustainable open innovation (S-OI), which has been defined by Bogers et al. (2020, p.1507) as "a distributed innovation process which is based on purposively managed knowledge flows across organizational boundaries, using pecuniary and non-pecuniary mechanisms in line with the organization's business model, thereby contributing to development that meets the needs of the present without compromising the ability of future generations to meet their own needs". In sum, S-OI involves all companies towards innovative solutions that satisfy the present while safeguarding the future.

To pursue these purposes and to be innovative, even agri-food companies could use crowdsourcing platforms. Through crowdsourcing, agribusinesses can harness online crowds by leveraging the collective power of brains to achieve innovation goals (Cillo et al., 2019). Considering the society inclination towards sharing opinions on digital platforms, crowdsourcing could be useful for agribusinesses to perfectly match consumer needs, reducing waste and increasing sustainability. Connected crowds have a direct impact on production processes, fostering product development and influencing demand. Moreover, crowdsourcing generates dynamic, complex, and "big" data, which are the main drivers for the adoption of Industry 4.0 (Leimeister et al., 2009; Bresciani, 2017). Thus, crowdsourcing platforms appear as one of the main tools for the realization of OI and of the S-OI in agri-food sector, as the interaction with consumers brings multiple benefits in terms of satisfaction and sustainability. However, crowdsourcing platforms can also be geared toward other stakeholders, such as suppliers. Extending crowdsourcing and OI to the entire supply chain is necessary to achieve greater sustainability goals. In detail, the driving force that should move agri-food companies 
is the constant search for sustainable shared value. Through platforms, agribusinesses should seek to collaborate with all stakeholders to promote solutions that fulfill current requirements without compromising the future generations: they should achieve S-OI.

Currently, traditional farming methods - in which the attention is focused on the mass production of agri-food - have yielded unsustainable environment and individuals' solutions (Chaurasia et al., 2020). Therefore, new requirements for the agri-food production re-design require innovative smart solutions both applied in farming fields and supply chain. Sustainability is a new area of profitability, and it may increase reputational aspects. Nonetheless, developing business strategies that closely align profit and sustainability is a major challenge and should be tackled with a collaborative approach (Bustinza et al., 2019). Collaboration enables companies to provide customized products and services to reduce waste and minimize inefficiencies. Further, collaborations would allow players to work in partnership, thereby fulfilling the expectations of all stakeholders. Following this perspective, crowdsourcing-based OI practices offer the possibility for companies to achieve a good level of sustainability while also working on innovation (Bogers et al., 2020). Therefore, OI might be described as a source of shared value among a multiplicity of players. The value-sharing idea is based on developing a shared vision - within an ecosystem - where both people and organizations work and innovate collectively (Du et al., 2016). Shared value refers then to active participation, interactions, and collaboration to reach greater social development.

\section{Agri-Food 4.0 and Open Innovation}

\section{Open Innovation, Digital Technologies and Knowledge Sharing in Agri-Food Industry}

The relationship between successful OI and digital technologies is well-rooted in the academic literature (Dodgson et al., 2006). Over the last decade, scholars have pointed out the existence of a significant interdependency between digital technologies implementation and 
organizational capabilities to exploit external information for innovation purposes (Dodgson et al., 2005). Indeed, supply-chain side technologies have proven effective in collecting information from suppliers - i.e., production processes data and product usage reports. Thus, these technologies may help managers in getting technical information about products' limitations and possible margins for future improvements (Ardito et al., 2020). Moreover, it has been observed how consumer-side technologies -i.e., digital communication technologies and e-commerce- could support the exchange of information companies and consumers (Rialti et al., 2018). Through these tools, henceforth, it is possible to gather more information than ever about consumers' preferences, additional features they desire about a product, and further services they may require. In this perspective, according to Chesbrough and Bogers (2014), businesses embracing OI through digital technologies and ideas' crowdsourcing could significantly increase their competitiveness and reduce the time-to-market of their products.

In recent times, such a phenomenon started to be evident also in the agri-food industry. Indeed, in the past, agri-food business innovation was mostly based on internal sources (Alfrance et al., 2004); yet, the diffusion of technologies made most of the agritech businesses more oriented toward OI (Cillo et al., 2019). One of the principal objectives of the adoption of digital technologies is strengthening the ties with other businesses participating in the supply chain (Ardito et al., 2019). Digital tools such as Industry 4.0 technologies once applied to agrifood businesses context are effective in shortening the supply chain, monitoring all the steps bringing a product to market, and dialoguing with stakeholders and consumers interested in businesses' offerings (Trivelli et al., 2019). Client-side digital technologies such as social media, crowdsourcing platforms, messaging instruments, and e-commerce platforms allow communication either with B2B or B2C clients (Rialti et al., 2018). Industry 4.0 technologies are thus fundamental for agri-food OI. These technologies allow the collection of data about consumers' preferences, willingness to pay a certain price, and daily usage of e-commerce 
(Vlacic et al., 2019). Annosi et al. (2020a) observed in this regard how agriculture and agrifood businesses might obtain useful insights from the crowd through digital technologies and use these insights to develop new products. Nosi et al. (2020) similarly assessed how digital technologies could help sustainable agricultural growers in communicating the novelties of their products in new markets and in better replying to consumers' requests for information. Faraoni et al. (2019) focused on the impact of grocery retailers' e-commerce platforms in proposing new offerings to emerging consumers' cohorts. The 4.0 technologies are then enablers of OI ventures concerning new product development and improvement of channels to reach consumers. Instead, the adoption of production and logistic sides' 4.0 technologies showed a disruptive potential in the realization of new agri-food products, as they are a pivotal factor in collaborative business models' innovation in agri-food businesses (Fertő et al., 2016). Digital technologies in the agri-food industry could allow the combination of supply chains. In particular, a business could develop systems to exchange real-time information, which in turn allows transmitting the inputs concerning new ideas that might be developed through the collaboration of more partners (Rialti et al., 2018a; Belaud et al., 2019). Aside from that, McKinsey Consulting observed how with 4.0 technologies, it is possible to monitor any phase in bringing a product to the market (Alicke et al., 2017). Therefore, through the 4.0 technologies, agri-food businesses could ensure the traceability of any ingredient of an agrifood product, for example, by using blockchain protocols monitoring suppliers (Wang and Somogyi, 2018; Bumblauskas et al., 2020).

Building on this, the adoption of 4.0 technologies has the potential to revolutionize the modern agri-food industry. These technologies could therefore create a digital continuum between supplier and final consumers (Lowry et al., 2019; Trivelli et al., 2019). For example, consumers may submit a new idea through a website or social media. Next, key account managers from the agri-food businesses could share the idea with suppliers (such as agri-food 
growers). Finally, the jointly developed product is proposed to consumers (Annosi et al., 2020a).

To implement successful OI strategies, as well as to exploit the most of benefits deriving from such a strategic approach, agri-food businesses should also rely on internal knowledge management practices and systems. Indeed, data and information from consumers and the supply chain require coherent systems to be analyzed. Digital data generated by the 4.0 technologies are undeniably in need of knowledge management systems and procedures to collect, share, store and analyze them (Santoro et al., 2018). Hereby, knowledge is not manageable and exploitable if it is not structured, diffused, and whether the company is lacking a shared culture, including knowledge diffusion (Del Giudice and Dalla Peruta, 2016). In this context, agri-food businesses' absorptive capacities are thereby fundamental to simultaneously manage stakeholders' networks while integrating external knowledge into practice. Absorptive capacity is indeed the innate potential of a business to recognize the value of information whilst envisioning its future usage in production processes (Kiessling et al., 2009). The interplay between internal knowledge collection, analysis and sharing processes is, hence, necessary to make all the internal and external stakeholders aware of the new ideas and to exchange opinions concerning a new product (Griffith et al., 2012; Manesh et al., 2020). Industry 4.0 technologies integrated with knowledge management procedures and systems could then express all their potential in fostering successful OI (Rialti et al., 2020). The same applies to any form of OI, regardless of the objective, including S-OI.

\section{Agri-Food Business and 4.0 Technologies: The Emergence of Agritechs}

Recent research on the agri-food industry and 4.0 technology have pointed out the emergence of a new typology of agri-food business: Agritech businesses (Spanaki et al., 2021). Agritechs have been identified as businesses actively embracing the 4.0 paradigm (Lowry et al., 2019). 
Accordingly, agritech business models inherently include digital technologies, the pursuit of maximum efficiency, consumers' centrism, short supply-chain, and attention toward sustainability (Annosi et al., 2020b). Most of such businesses, nowadays, are either startups or businesses in the earliest stages of their growth processes. Yet, as a consequence of the growing attention toward climate change and sustainability, number of agritechs is growing in the majority of western countries. On the one hand, climate changes have increased managers attention toward new technologies that may increase efficiency in agricultural production (King, 2017). Technology, indeed, provides the opportunity to deal with water scarcity (thanks to sensors allowing the monitoring of water flow to each cultivation) and to predict meteorological uncertainty better. On the other hand, technologies may reduce agri-food wastage (Agovino et al., 2019). Such a phenomenon occurs as technology allows for a better tracing and, consequently, a reduction in the quantity of damaged agri-food or in cold-chain interruptions.

According to the traditional categorization of agri-food businesses existing in most of the contexts -i.e., producers of agri-food products and goods, producers of supporting goods and service providers, and distributors of agri-food products (Caiazza and Volpe, 2012; 2014)three typologies of agritech businesses may be identified. They differ from each other in accordance with their position within the supply chain and the aim of technological implementation. Thus, it is possible to distinguish between agritech growers, agritech integrators, and agritech distributors (Marvin, 2018; Spanaki et al., 2021):

1) Agritech growers: businesses operating in traditional farming activities, yet integrating digital technologies. In this regard, these businesses mostly rely on big data analytics for meteorological forecasts, sensors and actuators for water dosage and greenhouses' temperature control, intelligent machines for harvesting (Lowry et al., 2019). Examples of Agritech growers include farmers using drones for pest control or 
plant growth monitoring. In a similar fashion, some farmers started to use GPS tracking on tractors to monitor harvesting progression (Spanaki et al., 2021).

2) Agritech integrators: businesses providing technological solutions or services for other ones operating in the agricultural supply chain. Hence, these kinds of agritech businesses act as consultants for agricultural businesses wishing to implement new technologies to improve their growing techniques, supply-chain or distribution. Software and hardware-related consulting and implementation represent, therefore, the core of their activities (Cillo et al., 2019). Similarly, businesses providing ancillary support in agricultural activities fall within this category.

3) Agritech distributors: businesses exploiting new digital technologies to improve the distribution of agricultural goods. In particular, they rely on technologies such as social vending platforms, social media for communication and mobile applications to be in touch with consumers and growers. In particular, with digital technologies, they monitor any shipment they are going to receive from a grower (thus ensuring quality) and monitor all the steps of bringing a product to consumers (Annosi et al., 2020b). Hence, these businesses rely most on digital technologies that may help them in reducing agrifood wastage and in shortening delivery time to consumers (Spanaki et al., 2021). As an example, BDA may allow them to predict consumers' demands, while blockchain protocols could allow them to monitor each sale (Rialti et al., 2019). Nowadays, most distributors promote smaller growers' sustainable production and short supply chain (i.e., Cortilia, Happy Dirt, GrubMarket).

Agritechs then hold the potential to improve the agri-food supply chain and to put in touch with several players existing in the agri-food industry. In this regard, they play a relevant role in revolutionizing the agri-food supply chain as we know it today. This notwithstanding, 
while such businesses rely on technology and knowledge management systems, how these two factors could influence S-OI in the agri-food industry need to be better conceptualized (Cillo et al., 2019; Spanaki et al., 2021).

\section{Case Study Background and Research Methodology}

To answer the hypothesized research questions, we adopted a single case study methodology. Data were collected during interviews conducted in an agritech distributor emerging in the Italian market. The selected procedure for data collection and analysis may be summarized as follow:

1) Selection of the case in relation to its significance among several different possibilities

2) Recognition of primary and secondary sources of data

3) Identification of principal topics of interest and development of semi-structured interviews to be administered to managers

4) Visit of the business and collection of data from managers

5) Collection of data from secondary sources (i.e., corporate website, social media, startup incubators' website, newspapers, publicly available economic data).

6) Triangulation of data from different sources

7) Manual analysis of the data

8) Propositions and conceptual framework development

In this perspective, the authors followed the methodological approach suggested by Yin (2011; 2015). First of all, a theme of research and a suitable case has been identified. Next, the context has been analyzed through multiple lenses by collecting data from different sources. A triangulation between different sources has then been performed. Specifically, data from 
different sources were compared in order to assess their veracity and to provide more meaningful insights. By doing so, it was possible to select the most relevant information to be included in the content analysis, which was performed manually without the assistance of digital tools (De Graaf and van der Vossen, 2013). Through the content analysis, the main themes and concepts were extrapolated from qualitative data. Building on these elements, a conceptual framework unpacking the phenomenon has been proposed (Eisenhardt, 1989).

\section{Case Description}

Alpha $^{1}$ is a startup based in Florence (Italy). It was established in 2019. In the same year, it was accepted for a business acceleration program by one of the most important incubators in central and southern Italy. Its mission is to shorten the agri-food supply chain. In particular, the aim of the firm is to purchase biological products from local producers and sell them to consumers within a certain distance (about 50 kilometers) from one of their warehouses (Corriere della Sera, 2020). The vision of the company concerns improving the sustainability of the agri-food supply chain in the long run. Additionally, the founders aim at providing smaller growers an outlet to sell their products without relying on grocery stores. It currently employs about 20 people, 5 of whom have managerial skills. Most of the employees are under-30 (i.e., Millennials).

Since the inception of COVID-19 confinement measures, Alpha turnaround increased significantly (almost $+50 \%$ YoY; La Nazione, 2020). Such growth is driven by consumers' preference toward online grocery shopping, thus, avoiding visits to crowded places (Faraoni et al., 2019; Wang et al., 2020). As a consequence, Alpha started a recruiting campaign over the last year to cope with increasing demand (Startupitalia.com, 2020). Due to this growth, Alpha

\footnotetext{
${ }^{1}$ The name of the business has been anonymized according to a binding agreement between the authors and the managers.
} 
looked at the potential of new emerging opportunities and how to defend its competitive positioning in the Tuscany Region.

Alpha falls within the realm of agritech distributors as it actively embraces the use of 4.0 technologies within the agri-food supply chain. The business, indeed, relies on a customary ERP based on sensors, tags, blockchain and mobile apps to collect orders from consumers, prepare delivery packages for customers and to trace the status and the quality of delivery. Consistently, through the technology, Alpha may bi-directionally communicate in real-time with growers and consumers and reduce any eventual waste of time and products. Alpha, in addition, uses digital communication technologies to collect feedbacks from consumers and to forecast their purchases.

\section{Data Collection and Analysis}

For this research, data from Alpha was collected in two rounds, three months apart. The approach used by authors to collect data is illustrated in Table 1. The authors also collected information from interviews of managers and also collected data from secondary external sources.

Table 1. Principal sources consulted by the authors.

\begin{tabular}{|c|c|c|}
\hline \multirow{10}{*}{ Sources } & \multirow{4}{*}{ Internal Sources } & Interviews with managers \\
\hline & & $\begin{array}{l}6 \text { Interviews (General Manager, Marketing } \\
\text { Manager, Information Manager, employees) }\end{array}$ \\
\hline & & Report, Data, etc.... \\
\hline & & Reports about Future Perspectives \\
\hline & \multirow{6}{*}{ Main External Sources } & Newspapers \\
\hline & & $\begin{array}{l}\text { Corriere della Sera (2020) - see link to documents } \\
\text { in the references }\end{array}$ \\
\hline & & $\begin{array}{l}\text { La Nazione (2020) - see link to documents in the } \\
\text { references }\end{array}$ \\
\hline & & Websites \\
\hline & & $\begin{array}{l}\text { Startupitalia.it (2020) - see link to the document } \\
\text { in the references }\end{array}$ \\
\hline & & $\begin{array}{l}\text { Nanabianca.it (2020) - see link to the document } \\
\text { in the references }\end{array}$ \\
\hline
\end{tabular}


The first round of interviews took place on 15th February 2021, while the second one took place on $14^{\text {th }}$ May 2021. The people interviewed included the general manager, the marketing manager, the information manager and some employees actively dealing with ERP. The total length of the interviews was $7 \mathrm{~h}$ and 40 minutes (approx.). The interviews were video recorded and later transcribed. A semi-structured interview was selected as the main methodology to question managers. This kind of interview allows the interviewer an opportunity to prepare questions about certain topics while letting respondents have a certain degree of freedom and the possibility to provide open-ended replies (Rowley, 2012). Additionally, semi-structured interviews help in collecting information about different themes deemed important by respondents.

The questionnaire developed for the interviews were about the following themes:

a) Typology of technologies used by Alpha and principal objectives of their usage

b) Ways followed by Alpha to pursue sustainability

c) OI strategies implemented by Alpha

d) Principal technologies enacting OI

e) How Alpha manages stakeholders' networks

f) Knowledge management tools and techniques used by Alpha

Data collected through the interviews were then triangulated using information from external sources (Yin, 2015). In particular, information from newspapers was extremely useful to integrate missing data concerning the company's mission, vision, and turnaround. Additionally, this information was used to better understand the product range of Alpha. Information from institutional websites was instead used to better understand how Alpha deals with consumers and suppliers. Next, information from internal reports was used to evaluate the 
full understanding of Alpha's activity and to draw the final implications. At the end of this process, a complete textual dataset concerning Alpha was obtained. A manual content analysis was performed in detail, and the authors looked at recurring themes, which were used to create a coding dictionary. Then, such themes were selected in the text, and principal associations existing in the dictionary were used to create pieces of evidence about the specific phenomenon. In this regard, the principal themes that emerged from the research are: 1) Collaboration with suppliers; 2) Consumer Feedbacks Management; 3) Use of 4.0 Technologies; 4) Promotion of Sustainability. Among these themes, the first two directly relate to OI and Crowdsourcing; the third one explains technologies as an enabler of OI, and the final one explains the possibility for OI to generate significant constructive effects on society. The main results of this process are summarized in the following section.

\section{Results and key findings}

The main resuls of the case study analysis have been associated with each other, interpreted and summarized consistently. The emergent themes were used to develop and hypothesize several propositions as explained in the following paragraphs. These propositions represent significant aspects emerged from our qualitative and explorative analysis which might be empirically tested by future researchers interested in the innovation of agri-food businesses.

\section{OI, increased competitiveness and pursuit of sustainability.}

Sustainability is one of the main objectives of Alpha. In this regard, the business aims at improving the soil usage ratio and promoting sustainable farming. Encouraging sustainable consumption by selling biological and organic products is another focal point in the business mission. To do so, sustainability is pursued through an S-OI-oriented approach. According to managers, collaborations with consumers and suppliers have been deemed fundamental in order 
to improve the efficiency of the whole supply chain. On the one hand, information from consumers' feedback is instrumental in identifying new products and future patterns of consumption. Alpha consequently developed a digital community of most engaged consumers willing to provide insights about expectations in terms of offerings. On the other hand, sustainability is achieved through open discussions with suppliers. Specifically, this exchange of information allows Alpha to improve delivery effectiveness and reduce wastage. Communications make the supply chain shorter and avoid agri-food storage problems. As it was assessed, "communication with consumers and suppliers allowed us to follow and approach, we defined as filiera colta (i.e., cultured supply chain), in which consumers are aware of the origin of each product and suppliers are sentient of the importance of short lead time” (Marketing Manager, $15^{\text {th }}$ February 2021). The intertwining between sustainability and competitive advantages and how these two objectives are reachable through S-OI, clearly emerged.

Hence, the authors developed the following proposition:

P1: Alpha embraced an S-OI approach to simultaneously pursue increased competitiveness and sustainability-related goals.

\section{Digital technologies and advance ERP to enact crowdsourcing-based S-OI}

The key to implementing successful S-OI strategies is represented by digital technologies (Dodgson et al., 2005; 2006). Using the technologies, Alpha is capable of collecting information about consumers' preferences, their interaction with online platforms (i.e., the number of clicks before a purchase), and their degree of satisfaction (Cillo et al., 2019; Rialti et al., 2020). Similarly, the business may bi-directionally communicate with them in regard to new products they may be interested in. Accordingly, digital communication technologies may allow collecting ideas from crowds of consumers, enacting crowdsourcing from the consumers' 
side. Bi-directional communication technologies could therefore allow Alpha to constantly connect with the crowd of consumers. Crowdsourcing-based S-OI strategies, anyway, may not bring the expected results if suppliers are not involved in the process. Hence, technologies to support supplier-side relationships are fundamental too (Fertö et al., 2016). Through the use of the ERP system, Alpha may monitor all the steps involved in bringing a product to the market, i.e., from the field to the table. In particular, each supply batch is traced, and, thus, quality is ensured. Such a system works according to blockchain protocols, so each batch entering and exiting the business is constantly monitored. In addition, the customary ERP also offers the possibility for suppliers to communicate information about potential new offerings. Therefore, it emerges that suppliers may propose new products to Alpha, which in turn decides whether Alpha is going to preserve them or place them into the market immediately according to consumers' demand. Alpha's ERP, therefore, represents a kind-of touchpoint between consumers and suppliers. Such contacts, while mediated by Alpha, allow consumers also to make a request to suppliers, much to Alpha's benefit, as it will manage the transaction. One of the strengths of such a mechanism is also represented by Alpha's use of big data from consumers' transactions, which allows the company to forecast emerging demands. In detail, it was assessed that "Alpha internally developed the ERP system. The possibility to collect data from all our stakeholders while leaving a certain degree of contact between them has always been in the founders' minds. Apart from collecting data, it was possible to develop a dialogue with everyone interested and to create new products, while ensuring sustainability" (Information Manager, $15^{\text {th }}$ February 2021). Obviously, business knowledge management skills prove fundamental in supporting such information systems. Specifically, managers observed how the contribution of Alpha's employees is fundamental for better development of product concepts and to communicate what can be produced and what cannot be produced to consumers and suppliers. 
Hence, the authors developed the following proposition:

P2: Digital technologies for communication allow to collect data from consumers' crowds. Advanced ERP systems, in addition, allow collecting information about potential new offerings from suppliers.

Outcomes of crowdsourcing-based S-OI.

Based on all the data collected from crowds, Alpha became capable of pursuing S-OI. The main outcome of this process is regarding the development of new products. In fact, consumer suggestions allowed to identify market niches not considered by direct competitors. Information from suppliers, similarly, allowed for improvement in processes and new procedures to better preserve agri-food. For example, Alpha started providing consumers with recipes kits in collaboration with chefs and growers. The openness of the business is also fundamental in order to be inclusive of restaurants wishing to provide new offerings during the pandemic closures. Several restaurants, accordingly, started to sell cakes or other products through Alpha over the last year. In this regard, the interviews revealed that "our approach allowed us to increase our product portfolio during the pandemic. Specifically, consumers -which were at home-started to ask us for specific products which were not in our catalog. We approached our suppliers, and with them, we proposed new alternatives. Over the last months, we asked our consumers some feedback about new products, and it emerged as they desired recipes-kits, we accordingly started to propose them. In addition, we also started to collaborate with restaurants to promote some products on our platforms" (Marketing Manager, $15^{\text {th }}$ February 2021).

Hence, the authors developed the following proposition:

P3: The main outcomes of crowdsourcing-based-S-OI are increased competitiveness, new production and distribution processes, and new offerings development. 
Anyway, such positive effects also came at a cost. It was necessary for Alpha to implement new hardware through the warehouses and to increase the computational capacity of the server to accommodate these changes.

\section{Shared Value Creation}

Collaborative approaches usually create value for partners. Shared value, which is a form of value creatable by businesses that may be shared with stakeholders, is a consequence of most S-OI strategies. Such an occurrence has been observed even in the Alpha's case. Collaborative strategies implemented by the management at Alpha provided consumers with their desired products. Similarly, suppliers increased their turnover as a consequence of increased sales or sales of more valuable products. Such a new value reverberated on any player in the supply chain, including Alpha.

Hence, the authors developed the following propositions:

P4: New processes and new offerings developed through crowdsourcing based OI enable the creation of shared value;

P5: Shared value reverberates on any stakeholder involved in its creation.

\section{Conceptual framework development}

Building on the previous findings and on the developed propositions, a conceptual framework/model has been developed, as shown in Figure 1. 
Figure 1. Conceptual Framework

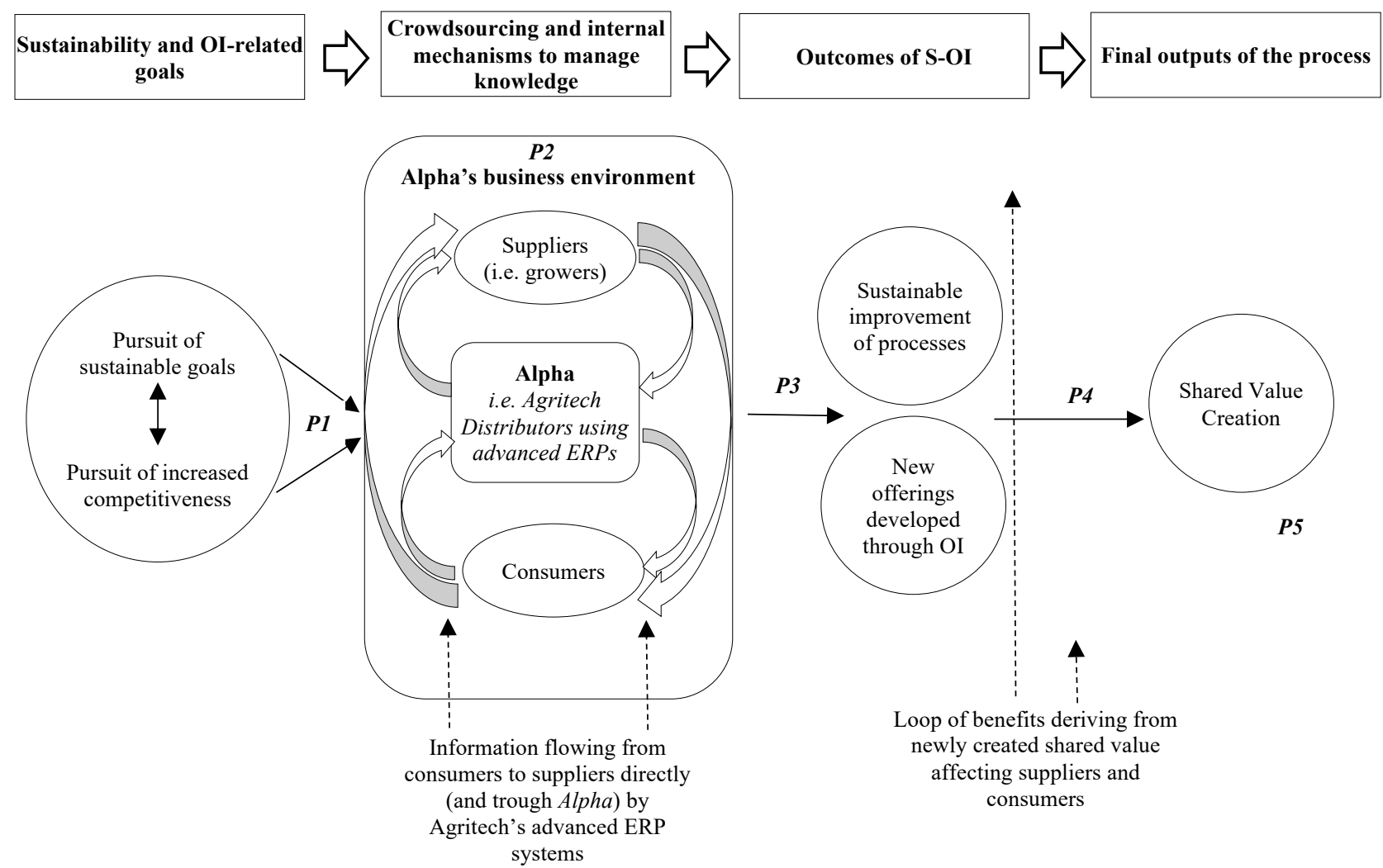

Source: Authors' own elaboration; OI: open innovation; S-OI: sustainable open innovation.

Hence, findings corroborate how agritechs' customary ERP systems and digital technologies to bi-directionally communicate with consumers and suppliers and could allow a constant information flow enacting OI strategies. It emerged that consumers might ask for new offerings' or developments directly from growers or through Alpha. In this way, OI and sustainability-related objectives may be achieved. Such a process may generate new forms of value that may be shared between Alpha, consumers, and suppliers.

\section{Discussion and Managerial Implications}

The main goal of the present study was to investigate the underlying mechanisms linking S-OI strategies, 4.0 technologies and sustainability within the agri-food businesses realm. To answer our research questions, we built on the pertinent literature and on empirical evidences that emerged from an emblematic inductive case study. This allowed us to propose a conceptual 
framework (Figure 1) that clearly and holistically shows the main features of the phenomenon under investigation, which have been summarized according to five theoretical propositions. This result is significant and relevant for both scholars and practitioners interested in the future of agritech/food businesses.

The first "pillar" emerging from our findings refers to the inseparable connectedness between sustainable goals pursuit and OI strategy adoption. These two aspects have to be implemented simultaneously by agritech managers in order to sustain their businesses in the long run (Bogers and Jensen, 2017). As Bogers et al. (2020) recently stated, S-OI represents the key challenge for entrepreneurs and managers, and this is particularly true in the agri-food sector, as our results showed. Actually, S-OI might be the strategic lever that management researchers have to deeply explore in order to better conceptualize what Porter and Kramer (2019) seminally labeled as "shared value creation". Although this notion has received scant attention from agri-food scholars, our qualitative inductive analysis evidently showed that the design and creation of effective collaborative strategies among both internal and external socioeconomic players could represent a significant competitive advantage in the agri-food context. Hence, the present research contributes to the literature on agri-food by showing how some of the agritechs - i.e., agri-food businesses embracing 4.0 - are more successful in S-OI. In particular, how they could better develop new offerings.

The second column of our model, as depicted in Figure 1, specifically elaborates on how to implement S-OI in the agritech realm practically. The boundaries of the business environment that were traditionally "closed" have to be open toward partnerships and alliances creation, especially among the three main players of the agri-food environment (Marvin, 2018): agritech distributors, suppliers, and customers. A continuously evolving knowledge-sharing mechanism between these players allows the agritech distributor to collect new ideas using the 4.0 digital technologies and, in this way, create tailored and ad-hoc products for customers. 
That is how competitive advantage might be created by the adoption of innovative systems (such as the advanced ERP system), which are able to better serve the needs and expectations of consumers. The intermediate function of agritech distributor between suppliers and customers emerged as fundamental in facilitating such an S-OI platform. These findings corroborate the role of internal procedures and systems to manage knowledge fluxes, even in the case of agritechs.

The final third element of our framework stresses the positive outcomes of exploiting S-OI to create shared value in a collaborative environment (Santoro et al., 2017). Specifically, as illustrated in Figure 1, a dynamic feedback loop is created, enabling a vicious circle among all the stakeholders involved in a technological revolution affecting the agri-food sector. One of the main outcomes of our theoretical and empirical investigation relies on the fact that any organization present on the sustainable/innovative-driven platform has to strategically leverage the flow of information, abilities, and capabilities. This might create a real collaborative ecosystem that dynamically generates knowledge transfer among the involved players (Annosi et al., 2020a; Rialti et al., 2018b).

Accordingly, it is possible to develop some suggestions for managers and practitioners. Alpha's case presents some best practices about OI management in the agri-food industry. As an example, it was observed that it is fundamental to include both suppliers and consumers to always match offering and demand. Specifically, if they can communicate with each other through an owned platform, it may be possible to reap the most advantages while reducing the overall business risk. Accordingly, Alpha is not required to increase its stocks of perishable products, while it will get the economic benefits of the transaction. Next, it is possible to recommend the importance of ad hoc developed information systems. Therefore, if the objectives of a company, in terms of OI and sustainability, are clearly stated, a customized information system (such as Alpha's ERP) could allow better collection and analysis of the 
right information at the right moment. Decision quality could, hence, be improved (Rialti et al., 2019b). Last, it emerged that amidst crises (such as the one caused by COVID-19), OI could represent a suitable strategy to be in touch with consumers and to address new needs.

\section{Limitations and Suggestions for Future Research}

Our study presents the main limitations of most of the researches based on qualitative methodology. Specifically, the five theoretical propositions are based on evidence related to a single inductive case study. While this is particularly relevant in the inductive and explorative investigation process, we strongly recommend that future researchers empirically test these propositions and our proposed theoretical framework (Figure 1) using a quantitative approach. For example, it would be interesting to test these assumptions through a survey-based methodology in order to collect hundreds of data from agri-food entrepreneurs and managers across different European regions - not only Italy as in our case - to assess potential dissimilarities in their feedbacks and insights.

Moreover, our study sheds light for future research focused on revealing the main disadvantages as perceived by all the stakeholders involved in the agritech business, not only internal players - such as stakeholders within the organization, for example, the distributor, as in our case study - but also key external stakeholders such as suppliers and customers.

Although we are still at the beginning of the investigation about sustainability, innovation, and business performance in the agri-food context, scholars and practitioners are increasingly aware of the importance of new technologies in agriculture, especially in the postpandemic era, which will be more and more characterized by the 4.0 technology adoption to be competitive and sustainable. 


\section{References}

Agovino, M., Cerciello, M., and Gatto, A. (2018). Policy efficiency in the field of food sustainability. The adjusted food agriculture and nutrition index. Journal of Environmental Management, Vol.218, pp.220-233.

Agrawal, A.K. and Rahman, Z. (2015), "Roles and resource contributions of customers in value co-creation”, International Strategic Management Review, Vol.3, No.1, pp.144-160.

Agrifood.tech (2018). Agritech, startup ed export: ecco il futuro dell'agroalimentare. Link: https://www.agrifood.tech/news-agrifood/agritech-startup-ed-export-futurodellagroalimentare/ (retrieved on $15^{\text {th }}$ February 2021).

Alfranca, O., Rama, R., and von Tunzelmann, N. (2004). Innovation spells in the multinational agri-food sector. Technovation, Vol.24, No.8, pp.599-614.

Alicke, K., Rexhausen, D., and Seyfert, A. (2017). Supply Chain 4.0 in consumer goods. Mckinsey $\quad \& \quad$ Company, 1-11. Link: https://www.mckinsey.com/ /media/McKinsey/Industries/Consumer\%20Packaged\%2 0Goods/Our\%20Insights/Supply\%20Chain $\% 204 \% 200 \% 20$ in $\% 20$ consumer\%20goods/ Supply-Chain-4-0-in-consumer-goods-vf.pdf (Retrieved on 10th January 2021).

Annosi, M. C., Brunetta, F., Capo, F., and Heideveld, L. (2020b). Digitalization in the agrifood industry: the relationship between technology and sustainable development. Management Decision, Vol.58, No.8, pp.1737-1757.

Annosi, M. C., Marzi, G., Ciampi, F., and Rialti, R. (2020a). An ambidextrous approach to practice-based innovation for social product development: lessons from a Dutch company. IEEE Transactions on Engineering Management. DOI: 10.1109/TEM.2020.2977976. 
Ardito, L., Petruzzelli, A. M., Panniello, U., and Garavelli, A. C. (2019). Towards Industry 4.0: Mapping digital technologies for supply chain management-marketing integration. Business Process Management Journal, Vol.25, No.2, pp.323-346.

Ardito, L., Petruzzelli, A. M., Dezi, L., and Castellano, S. (2020). The influence of inbound open innovation on ambidexterity performance: does it pay to source knowledge from supply chain stakeholders?. Journal of Business Research, Vol.119, pp.321-329.

Belaud, J. P., Prioux, N., Vialle, C., and Sablayrolles, C. (2019). Big data for agri-food 4.0: Application to sustainability management for by-products supply chain. Computers in Industry, Vol.111, pp.41-50.

Belyaeva, Z., Rudawska, E.D. and Lopatkova, Y. (2020). Sustainable business model in food and beverage industry - a case of Western and Central and Eastern European countries. British Food Journal, Vol.122, No.5, pp.1573-1592.

Bogers, M., and Jensen, J. D. (2017). Open for business? An integrative framework and empirical assessment for business model innovation in the gastronomic sector. British Food Journal, Vol.119, No.11, pp.2325-2339.

Bogers, M., Chesbrough, H., and Strand, R. (2020). Sustainable open innovation to address a grand challenge. British Food Journal, Vol.122, No.5, pp.1505-1517

Bresciani, S. (2017). Open, networked and dynamic innovation in the food and beverage industry. British Food Journal, Vol.119, No.11, pp.2290-2293.

Bresciani, S., Ferraris, A., Santoro, G. and Nilsen, H.R. (2016). Wine sector: companies' performance and green economy as a means of societal marketing. Journal of Promotion Management, Vol.22, No.2, pp.251-267.

Bumblauskas, D., Mann, A., Dugan, B., an Rittmer, J. (2020). A blockchain use case in food distribution: Do you know where your food has been?. International Journal of Information Management. DOI: https://doi.org/10.1016/j.ijinfomgt.2019.09.004 
Bustinza, O. F., Gomes, E., Vendrell-Herrero, F., and Baines, T. (2019). Product-service innovation and performance: the role of collaborative partnerships and R\&D intensity. $R \& D$ Management, Vol.49, No.1, pp.33-45.

Caiazza, R. and Volpe, T. (2012). The global agro-food system from past to future. China-USA Business Review, Vol.11, No.7, pp.919-929.

Caiazza, R. and Volpe, T. (2014). Agro-food firms' competitiveness: made in Italy in the world. International Review of Management and Business Research, Vol.3, No.2, pp.17901796.

Cavaye, A. L. (1996). Case study research: a multi-faceted research approach for IS. Information Systems Journal, Vol.6, No.3, pp.227-242.

Chaurasia, S. S., Kaul, N., Yadav, B., and Shukla, D. (2020). Open innovation for sustainability through creating shared value-role of knowledge management system, openness and organizational structure. Journal of Knowledge Management, Vol.24, No.10, pp.24912511.

Chesbrough, H. W. (2003). Open innovation: The new imperative for creating and profiting from technology. Harvard Business Press.

Chesbrough, H. (2020). To recover faster from Covid-19, open up: Managerial implications from an open innovation perspective. Industrial Marketing Management, Vol.88, pp.410-413.

Chesbrough, H., and M. Bogers. (2014). "Explicating Open Innovation: Clarifying an Emerging Paradigm for Understanding Innovation." In New Frontiers in Open Innovation, edited by H. Chesbrough, W. Vanhaverbeke, and J. West, 3-28. Oxford: Oxford University Press

Chesbrough, H., Heaton, S., and Mei, L. (2021). Open innovation with Chinese characteristics: a dynamic capabilities perspective. $R \& D$ Management, Vol.51, No.3, pp.247-259. 
Cheng, X., Fu, S., De Vreede, T., De Vreede, G. J., Seeber, I., Maier, R., and Weber, B. (2020). Idea Convergence Quality in Open Innovation Crowdsourcing: A Cognitive Load Perspective. Journal of Management Information Systems, Vol.37, No.2, pp.349-376.

Cillo, V., Rialti, R., Bertoldi, B., and Ciampi, F. (2019). Knowledge management and open innovation in agri-food crowdfunding. British Food Journal, Vol.121, No.2, pp.242258.

Corriere della Sera (2020). Oplì: il progetto che vuole azzerare la distanza tra cibo e consumatori. https://video.corriere.it/viaggi/opli-progetto-che-vuole-azzerare-distanzacibo-consumatori/1eaf968c-5ef6-11ea-bf24-0daffe9dc780 (Retrieved, 10th January, 2021).

Costa, A.I.A., Greco, M., Grimaldi, M., Cricelli, L. and Corvello, V. (2016). Interorganisational innovation processes in the European food and drink industry. International Journal of Management and Enterprise Development, Vol.15, No.2-3, pp.191-208.

Costa, A.I.A., Schoolmeester, D., Dekker, M. and Jongen, W.M.F. (2007). To cook or not to cook: a means-end study of the motivations behind meal choice. Food Quality and Preference, Vol.18, No.1, pp.77-88.

Cotet, C.E., Deac, G.C., Deac, C.N., and Popa, C.L. (2020). An innovative industry 4.0 cloud data transfer method for an automated waste collection system. Sustainability, Vol.12, No.5, pp.1839-1860.

De Graaf, R., and van der Vossen, R. (2013). Bits versus brains in content analysis. Comparing the advantages and disadvantages of manual and automated methods for content analysis. Communications, Vol.38, No.4, pp.433-443.

Del Giudice, M., and Della Peruta, M.R. (2016). The impact of IT-based knowledge management systems on internal venturing and innovation: a structural equation 
modeling approach to corporate performance. Journal of Knowledge Management, Vol.20, No.3, pp.484-498

Dodgson, M. and Gann, D.M. and Salter, A. (2005). Think, Play, Do: Technology and the New Innovation Process. Oxford: Oxford University Press

Dodgson, M., Gann, D., and Salter, A. (2006). The role of technology in the shift towards open innovation: the case of Procter \& Gamble. $R \& D$ Management, Vol.36, No.3, pp.333346.

Du, S., Yalcinkaya, G. and Bstieler, L. (2016). Sustainability, social media driven open innovation, and new product development performance. Journal of Product Innovation Management, Vol.33, No.1, pp.55-71.

Eisenhardt, K. M. (1989). Building theories from case study research. Academy of Management Review, Vol.14, No.4, pp.532-550.

Faraoni, M., Rialti, R., Zollo, L., and Pellicelli, A. C. (2019). Exploring e-Loyalty Antecedents in B2C e-Commerce: Empirical Results from Italian Grocery Retailers. British Food Journal, Vol.121, No.2, pp.574-589.

Fertő, I., Molnár, A., and Tóth, J. (2016). Borderless ideas-open innovation in the Hungarian food chain. British Food Journal, Vol.118 No.6, pp.1494-1515

Franceschelli, M.V., Santoro, G. and Candelo, E. (2018). Business model innovation for sustainability: a food start-up case study. British Food Journal, Vol.120, No.10, pp. 2483-2494.

Galati, F., Bigliardi, B., and Petroni, A. (2016). Open innovation in food firms: Implementation strategies, drivers and enabling factors. International Journal of Innovation Management, Vol.20, No.3, pp.1650- 1662. 
Griffith, D. A., Kiessling, T., and Dabic, M. (2012). Aligning strategic orientation with local market conditions: Implications for subsidiary knowledge management. International Marketing Review, Vol.29, No.4, pp.379-402.

Grimsby, S., and Kure, C.F. (2019). How open is food innovation? The crispbread case. British Food Journal, Vol.121, No.4, pp.950-963.

Hervas-Oliver, J. L., Sempere-Ripoll, F., and Boronat-Moll, C. (2021). Technological innovation typologies and open innovation in SMEs: Beyond internal and external sources of knowledge. Technological Forecasting and Social Change, Vol.162. DOI: 10.1016/j.techfore.2020.120338

Kafetzopoulos, D., Vouzas, F., and Skalkos, D. (2020). Developing and validating an innovation drivers' measurement instrument in the agri-food sector. British Food Journal, Vol.122, No.4, pp.1199-1214.

Kamble, S. S., Gunasekaran, A., and Sharma, R. (2020). Modeling the blockchain enabled traceability in agriculture supply chain. International Journal of Information Management. DOI: https://doi.org/10.1016/j.ijinfomgt.2019.05.023

Kiessling, T. S., Richey, R. G., Meng, J., and Dabic, M. (2009). Exploring knowledge management to organizational performance outcomes in a transitional economy. Journal of World Business, Vol.44, No.4, pp.421-433.

King, A. (2017). Technology: The future of agriculture. Nature, 544(7651), S21-S23.

La Nazione (2020). Covid, l'impegno solidale delle startup del network di Nana Bianca durante l'emergenza. https://www.lanazione.it/cronaca/nana-bianca-1.5174605 (Retrieved, 10th January, 2021).

Lefebvre, V. M., De Steur, H., and Gellynck, X. (2015). External sources for innovation in food SMEs. British Food Journal, Vol.117, No.1, pp.412-430. 
Lowry, G. V., Avellan, A., and Gilbertson, L. M. (2019). Opportunities and challenges for nanotechnology in the agri-tech revolution. Nature Nanotechnology, Vol.14, No.6, pp.517-522.

Maksimović, M., Vujović, V., and Omanović-Miklićanin, E. (2015). Application of internet of things in food packaging and transportation. International Journal of Sustainable Agricultural Management and Informatics, Vol.1, No.4, pp.333-350.

Manesh, M. F., Pellegrini, M. M., Marzi, G., and Dabic, M. (2020). Knowledge management in the fourth industrial revolution: Mapping the literature and scoping future avenues. IEEE Transactions on Engineering Management, Vol.68, No.1, pp.289-300.

Marvin, D.R. (2018). The second green revolution will bring agri-tech breakthroughs to growers. Industrial Biotechnology, Vol.14, No.3, pp.120-122.

Miglietta, N., Battisti, E., and Campanella, F. (2017). Value maximization and open innovation in food and beverage industry: evidence from US market. British Food Journal, Vol.119, No.11, pp.2477-2492.

Nanabianca.it (2020). STARTUP STUDIO ALL'INSEGNA DELL'INNOVAZIONE. Link: https://nanabianca.it/startup-studio (Retrieved on 10th January 2021).

Nosi, C., Zollo, L., Rialti, R., and Ciappei, C. (2019). Sustainable consumption in organic food buying behavior: the case of quinoa. British Food Journal, Vol.122, No.3, pp.976-994.

Piller, F.T. (2010). Open innovation with customers: crowdsourcing and co-creation at Threadless. Available at SSRN 1688018.

Porter, M.E., and Kramer, M.R. (2019). Creating shared value. In Managing sustainable business (pp. 323-346). Springer, Dordrecht.

Rialti, R., Caliandro, A., Zollo, L., and Ciappei, C. (2018). Co-creation experiences in social media brand communities: Analyzing the main types of co-created experiences. Spanish Journal of Marketing-ESIC, Vol.22, No.2, pp.122-141. 
Rialti, R., Marzi, G., Silic, M., and Ciappei, C. (2018). Ambidextrous organization and agility in big data era. Business Process Management Journal, Vol.24, No.5, pp.1091-1109.

Rialti, R., Marzi, G., Ciappei, C., and Busso, D. (2019a). Big data and dynamic capabilities: a bibliometric analysis and systematic literature review. Management Decision, Vol.57, No.8, pp.2052-2068.

Rialti, R., Zollo, L., Ferraris, A., and Alon, I. (2019b). Big data analytics capabilities and performance: Evidence from a moderated multi-mediation model. Technological Forecasting and Social Change, $149 . \quad$ DOI: https://doi.org/10.1016/j.techfore.2019.119781

Rialti, R., Marzi, G., Caputo, A., and Mayah, K. A. (2020). Achieving strategic flexibility in the era of big data. Management Decision, Vol.58, No.8, pp.1585-1600.

Rowley, J. (2012). Conducting research interviews. Management Research Review, Vol.35, No.3-4, pp.260-271.

Rüßmann, M., Lorenz, M., Gerbert, P., Waldner, M., Justus, J., Engel, P., and Harnisch, M. (2015). Industry 4.0: The future of productivity and growth in manufacturing industries. Boston Consulting Group, Vol.9, No.1, pp.54-89.

Saguy, I. S. (2016). Challenges and opportunities in food engineering: Modeling, virtualization, open innovation and social responsibility. Journal of Food Engineering, Vol.176, No.28.

Santoro, G., Vrontis, D., and Pastore, A. (2017). External knowledge sourcing and new product development. British Food Journal, Vol.119, No.11, pp.2373-2387.

Santoro, G., Vrontis, D., Thrassou, A., and Dezi, L. (2018). The Internet of Things: Building a knowledge management system for open innovation and knowledge management capacity. Technological Forecasting and Social Change, Vol.136, pp.347-354. 
Soto-Acosta, P. and Cegarra-Navarro, J.G. (2016), "New ICTs for knowledge management in organizations”, Journal of Knowledge Management, Vol.20, No.3, pp.417-422.

Sousa-Zomer, T. T., and Miguel, P. A. C. (2018). Sustainable business models as an innovation strategy in the water sector: An empirical investigation of a sustainable product-service system. Journal of Cleaner Production, Vol.171, S119-S129.

Spanaki, K., Sivarajah, U., Fakhimi, M., Despoudi, S., and Irani, Z. (2021). Disruptive technologies in agricultural operations: A systematic review of AI-driven AgriTech research. Annals of Operations Research. DOI: https://doi.org/10.1007/s10479-020$\underline{03922-Z}$

Startupitalia.com (2020). 30 nuove imprese, 140 posti di lavoro, 1600 progetti candidati. I risultati di HUBBLE al termine della quinta edizione. Link: https://startupitalia.eu/120928-20200127-30-nuove-imprese-140-posti-di-lavoro-1600progetti-candidati-i-risultati-di-hubble-al-termine-della-quinta-edizione (Retrieve on 10th January 2021).

Tardivo, G., Thrassou, A., Viassone, M., and Serravalle, F. (2017). Value co-creation in the beverage and food industry. British Food Journal, Vol.119, No.11, pp.2359-2372.

Tiscini, R., Testarmata, S., Ciaburri, M., and Ferrari, E. (2020). The blockchain as a sustainable business model innovation. Management Decision. DOI: https://doi.org/10.1108/MD$\underline{09-2019-1281}$

Trivelli, L., Apicella, A., Chiarello, F., Rana, R., Fantoni, G. and Tarabella, A. (2019). From precision agriculture to Industry 4.0: Unveiling technological connections in the agrifood sector. British Food Journal, Vol.121, No.8, pp.1730-1743.

UK Government (2013). A UK Strategy for Agricultural Technologies. Link: https://assets.publishing.service.gov.uk/government/uploads/system/uploads/attachme 
nt_data/file/227259/9643-BIS-UK_Agri_Tech_Strategy_Accessible.pdf (Retrieved on 15th February 2021).

Vlačić, E., Dabić, M., Daim, T., and Vlajčić, D. (2019). Exploring the impact of the level of absorptive capacity in technology development firms. Technological Forecasting and Social Change, Vol.138, pp.166-177.

Wang, O., and Somogyi, S. (2018). Consumer adoption of online food shopping in China. British Food Journal, Vol.120, No.12, pp.2868-2884.

Wang, Y., Xu, R., Schwartz, M., Ghosh, D., and Chen, X. (2020). COVID-19 and retail grocery management: insights from a broad-based consumer survey. IEEE Engineering Management Review, Vol.48, No.3, pp.202-211.

Wicaksono, T., Hossain, M. B., and Illés, C. B. (2021). Prioritizing Business Quality Improvement of Fresh Agri-Food SMEs through Open Innovation to Survive the Pandemic: A QFD-Based Model. Journal of Open Innovation: Technology, Market, and Complexity, Vol.7, No.2, pp.156-168.

Wolfert, S., Ge, L., Verdouw, C., and Bogaardt, M. J. (2017). Big data in smart farming-a review. Agricultural Systems, Vol.153, pp.69-80.

$\mathrm{Xu}$, L. D., Xu, E. L., and Li, L. (2018). Industry 4.0: state of the art and future trends. International Journal of Production Research, Vol.56, No.8, pp.2941-2962.

Yin, R. K. (2011). Applications of case study research. Thousand Oaks (CA), Sage Publishing. Yin, R. K. (2015). Qualitative research from start to finish. New York (NY), Guilford Publications. 